\title{
Duration of keypecks in variable-interval schedules of reinforcement
}

\author{
JOSEPH G. WILLIAMS and EDWARD K. CROSSMAN \\ Utah State University, Logan, Utah 84322
}

\begin{abstract}
An experiment was conducted to determine the duration of pigeons' keypecks during three separate variable-interval (VI) schedules of reinforcement. Pigeons were exposed to VI 30-sec, VI 60 -sec, and VI 120-sec schedules of reinforcement for 20 sessions each. Response durations were analyzed in terms of VI schedule value, location in time during the interreinforcement interval, and local patterns of short- and long-duration pecks. For three out of four birds, the mean response duration was reliably longer for the VI 30-sec schedule than for the VI 120-sec schedule. Results for the VI 60-sec condition were equivocal. Mean duration of response was constant throughout the VI interval, showing no change over time. No specific pattern of long and short pecks was detected. The results confirm the existence of a range of response durations during VI schedules of reinforcement and suggest that duration of response varies with VI schedule changes.
\end{abstract}

Schwartz and Williams (1972) suggested that keypeck responses in pigeons could be differentiated into two fairly distinct classes on the basis of the duration of the response. Duration of response can be conveniently specified by the time in milliseconds that a keypeck response holds open a switch. Keypecks produced during procedures in which pecks prevented the delivery of food (omission procedures) were generally shorter (20 msec or less) than those found under some operant schedules (fixed interval, FI, and fixed ratio, FR). Schwartz and Williams (1972) reported that shortduration pecks could not be increased in frequency by making food presentation contingent on their occurrence. This was not true of longer pecks (40-100 msec). Longer pecks increased in frequency when food was presented following their occurrence.

Schwartz and Williams' (1972) data suggested that short-duration pecks were reflexive and longer durations were operant. Their conclusions were extended by Schwartz (1977a, 1977b), Schwartz and Gamzu (1977), and Schwartz, Hamilton, and Silberberg (1975).

The data generated by Schwartz and others (Schwartz, 1977a, 1977b; Schwartz et al., 1975; Schwartz \& Williams, 1972) were extremely intriguing. For the first time, it seemed that the interaction of respondent and operant systems of control could be measured and quantified within a single experimental preparation. The fact that keypecks could be respondents under operant schedules suggested that some longstanding problems in

Portions of these data were presented at the 1978 meetings of the Rocky Mountain Psychological Association, Denver, Colorado. The authors wish to acknowledge the assistance of Nancy L. Eldred in preparing the figure. Requests for reprints should be directed to Joseph G. Williams, Exceptional Child Center, UMC 68, Utah State University, Logan, Utah 84322. operant psychology might be solved or at least partially explained by considering respondent sources of control.

However, a study subsequently appeared that suggested that some of the basic suggestions by Schwartz might be incorrect. Ziriax and Silberberg (1978) questioned Schwartz and Williams' (1972) contention that pecks could be dichotomized into operant and reflexive on the basis of duration. Ziriax and Silberberg suggest that response duration increases as response strength increases. They define response strength as a direct function of response rate for schedules in which rate of response is a meaningful measure (FI, FR, VI, $\mathrm{VR}, \ldots$, etc.) or the reciprocal of response latency in which rate is not appropriate (omission, CRF, automaintenance, DRL). This explanation holds that response duration, rather than being related to respondent and operant control, is related to response strength.

The present study investigated the duration of response over three VI schedules of reinforcement (VI $30 \mathrm{sec}$, VI $60 \mathrm{sec}$, and VI $120 \mathrm{sec}$ ). Collection of data during different parts of the VI interval allowed comparison with existing FI and FR data (Schwartz, 1977a). In addition, collection of rate and duration data will allow reference to be made to the Ziriax and Silberberg (1978) hypothesis.

\section{METHOD}

\section{Subjects}

Four adult, experimentally naive homing pigeons of undetermined sex were deprived to $80 \%$ of their free-feeding weights. Water was continuously available in individual home cages.

\section{Apparatus}

The experimental enclosure was $59.8 \times 24.0 \times 25.0 \mathrm{~cm}$ high. The front panel $(24.0 \times 25.0 \mathrm{~cm})$ was stainless steel and contained three keys $2.54 \mathrm{~cm}$ in diameter. Only the right key was used. The left key was dark and inoperative, and the center key 
was taped. The right key was capable of transillumination with red light. The key required a force of $.1 \mathrm{~N}$ in order to record a response. Two white $28-\mathrm{V}$ dc (G.E. 1820) bulbs provided houselight illumination. These were mounted $11 \mathrm{~cm}$ on either side of the midline of the chamber and $30 \mathrm{~cm}$ above the floor. The hopper opening was square, $14.7 \mathrm{~cm}$ from the left wall and $5 \mathrm{~cm}$ above the floor. Two white G.E. 1820 bulbs provided illumination of the hopper during food presentation. The enclosure was housed inside a sound-attenuating chamber, equipped with an exhaust fan, and white noise was supplied continuously to the experimental room. An IMSAI 8080 (IMS Associates) microcomputer controlled experimental events and collected the data. This computer recorded responses as short as $4 \mathrm{msec}$. The computer was connected to the experimental environment through a custom-designed interface that, together with computer software and other hardware components used in the experiment, are described elsewhere (Crossman \& Williams, 1978). The custom-designed interface and the computer measured durations in the following manner: Durations were recorded from the time the electrical signal was removed from the normally closed contact of the response key's microswitch and came in contact with the normally open contact of the microswitch until the signal was removed from the normally open contact. That is, the response was timed as long as the key was depressed.

\section{Procedure}

Autoshaping. Following hopper training, the birds were trained to keypeck using the general autoshaping procedure described by Brown and Jenkins (1968). Two birds established pecking during the first session of autoshaping; the remaining two birds required one additional autoshaping session each.

Following the session in which pecking was established, the requirement was changed to a VI 20 -sec schedule of reinforcement. This schedule was in effect for one session for all birds, after which a VI 40-sec schedule was in effect for one session. In the next session, the first experimental condition (VI $60 \mathrm{sec}$ ) was introduced, and all birds were run for 20 sessions at each of the three experimental values (VI $60 \mathrm{sec}$, VI $30 \mathrm{sec}$, and VI $120 \mathrm{sec}$ ). Thereafter, two birds were exposed to VI $30 \mathrm{sec}$ and VI $120 \mathrm{sec}$, in that order (Subjects C6 and C16), and two were exposed to VI $120 \mathrm{sec}$ and VI $30 \mathrm{sec}$, in that order (C17 and $\mathrm{C18}$ ). The experimental values were chosen so as to provide a wide range of common VI values that were known to produce substantial responding. The formula presented by Catania and Reynolds (1968, p. 381) was used to generate the VI values.

\section{RESULTS}

Figure 1 shows the mean response durations and response rates across the three VI values studied. Mean durations varied between 12 and $30 \mathrm{msec}$ for three out of four birds (C16, C17, C18); the fourth (C6) varied from 23 to $41 \mathrm{msec}$. There is a consistent difference in the mean duration of response between two of the conditions (VI $30 \mathrm{sec}$ and VI $120 \mathrm{sec}$ ) for three of the four birds (C16, C17, C18), with VI $30 \mathrm{sec}$ producing responses of longer duration relative to VI $120 \mathrm{sec}$. The VI $60 \mathrm{sec}$ seems to be a pivot point, in which the mean duration of response is more similar to the mean duration of response for VI $30 \mathrm{sec}$ in some cases (C16, C17), whereas the data seem more similar to VI $120 \mathrm{sec}$ for the remaining bird (C18). For C6, however, the mean response duration was lower at VI $30 \mathrm{sec}$ than at VI $120 \mathrm{sec}$.

Ziriax and Silberberg (1978) suggest that response

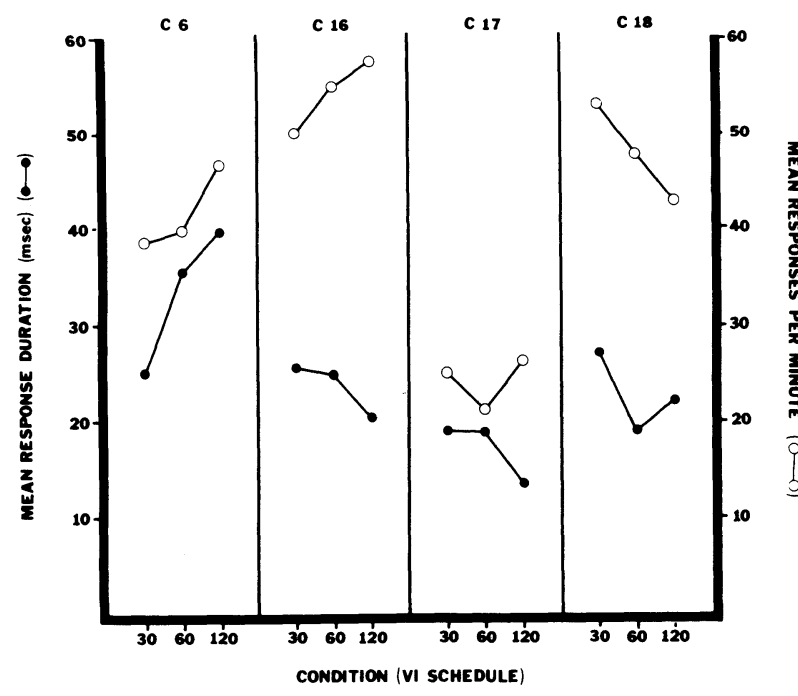

Figure 1. Mean rate of response (responses per minute) for each subject over the last 5 days of each condition and the mean response duration in milliseconds for each subject over the last 5 days of each condition.

duration increases as response strength increases. Thus, low response rates should produce more short-duration responses, and high rates should produce more longduration responding. The present procedures allowed a within-subjects comparison of the relationships between rate and duration. Figure 1 clearly shows, at least with the present data, that a simple relationship between response rate and response duration does not exist.

Another issue of interest is the question of the degree of interdependence of successive response durations. That is, do shorter pecks tend to occur after other shorter pecks? Do pecks of certain durations tend to alternate? Do any other patterns occur consistenly? Analysis of these questions is somewhat difficult. At one level, visual inspection of the durations of up to 5,000 responses for each bird revealed no such patterns. If a statistical analysis is attempted, the question of response independence is critical. Independence is unlikely, because the responses in question are produced by a single subject and the responses are produced very close together in time. With the assumption of independence severely violated, one can use statistical measures only descriptively, and a conservative interpretation of any statistically significant finding is indicated.

In order to determine if a relationship existed between successive pecks, a Pearson product-moment correlation was performed between pairs of successive response durations for representative sessions. Thus, for the sequence of response durations $(\mathrm{N}, \mathrm{N}+1, \mathrm{~N}+2$, etc.), $\mathrm{N}$ and $\mathrm{N}+1$ formed the first pair of observations that was used to compute the correlation; $\mathrm{N}+1$ and $\mathrm{N}+2$ were correlated next, and so on. None of these correlations was statistically significant at the $5 \%$ level. 


\section{DISCUSSION}

The present experiment found that mean durations of response under a VI 30 -sec schedule of reinforcement were longer than response durations produced under a VI 120-sec schedule of reinforcement. This difference was small but consistent for three of the four subjects. Several explanations of these findings are possible.

It could be the case that Ziriax and Silberberg's (1978) proposal that response strength controls duration of response would account for the present data. In the present study, data that directly related to the Ziriax and Silberberg (1978) hypothesis are available in Figure 1. Two out of the four birds (C6 and C18) support Ziriax and Silberberg's (1978) contention that, as response strength increases (as represented by rate of response), duration of response increases. Two birds (C16 and C17) show the opposite relationship. In accounting for the present data in terms of the Ziriax and Silberberg (1978) hypothesis, it is necessary to suppose that response strength for Subjects $\mathrm{C} 16$ and C17 was not accurately indicated by the response rate that occurred during these schedules of reinforcement.

Another explanation of the present data is the possibility that duration of response is controlled, perhaps indirectly, by the density of reinforcement. It would be reasonable to suggest that the greater density of food reinforcement on the VI 30-sec schedule places a greater proportion of the responses within an unknown but presumable limited temporal distance from reinforcement. Responses closely followed in time by reinforcement have a higher response strength than those farther in time from reinforcement (de Villiers, 1977). Thus, proportionally more responses would have high response strength on the schedule with higher reinforcement density. According to Ziriax and Silberberg (1978), higher response strength should produce longer duration keypecks. Hence, more pecks would be of longer duration on a schedule rich in food reinforcement.

Several problems exist with this explanation. First, if this were the case, some sort of temporal patterning should exist within a VI interval; more short-duration responses should occur immediately following reinforcement, and more long-duration pecks should occur later in the interval. Examination of mean duration during sections of the interval showed there was, in fact, a relatively constant mean duration of response throughout the VI interval. Second, Schwartz (1977a), while investigating another issue, ran the same group of birds on FR 40, FR 80, FI 1-min, and FI 2-min schedules. He reported that no differences in response durations were found between the two values of each of these schedules. If density of reinforcement were the explanation of the different response durations at VI $30 \mathrm{sec}$ and VI $120 \mathrm{sec}$, then the same argument should hold for the two schedules that Schwartz (1977a) investigated.

The present data must be regarded as inconclusive with regard to the Ziriax and Silberberg (1978) hypothesis that duration of response is controlled by response strength. As such, the competing explanations of Schwartz (Schwartz, 1977a, 1977b; Schwartz \& Gamzu, 1977; Schwartz \& Williams, 1972) and Ziriax and Silberberg (1978) must still be regarded as viable.

Another difference between the present data and other data reported by Schwartz and his colleagues and Ziriax and Silberberg (1978) is that the absolute duration of response is considerably shorter for the present data than for other reported operant schedules. Schwartz and Williams (1972) reported that median keypeck durations for FI and FR were in the 30- to 40-msec range, and other response durations under operant schedules investigated by Schwartz et al. (1975) were roughly equivalent. The absolute response durations in the present study are clearly shorter. Although the reason for these differences in absolute response duration is not known, the likely candidate is the different manner in which keypecks were recorded, described above. Schwartz (1977a) found that early in the interval during the FIs, there were more short-duration pecks than later in the interval. With FRs, the reverse was true: More long-duration pecks occurred early in the interval. This pattern of short- and long-duration responses did not emerge in the present data. A likely explanation of the differences in the patterns of the long- and short-duration keypecks among VI, FR, and FI schedules is that the fixed relationship between reinforcement and time in the case of the FI schedule and reinforcement and responses in the case of the FR schedule are not present in the VI schedule. The lack of these fixed relationships may have acted to destroy the patterns that might otherwise have developed.

The present data support the existence of a range of response durations during VI schedules of reinforcement. They also suggest that shorter VI schedules produce longer mean durations of response than do longer VI schedules. The duration of response was not found to change over the VI interval.

\section{REFERENCES}

Brown, P. L., \& Jenkins, H. M. Autoshaping of the pigeon's keypeck. Journal of the Experimental Analysis of Behavior, 1968, 11, 1-8.

Catania, A. C., \& Reynolds, G. S. A quantitative analysis of responding maintained by interval schedules of reinforcement. Journal of the Experimental Analysis of Behavior, 1968, 11, 327-383.

Crossman, E. K., \& Williams, J. G. A multi-user on-line 8080 microcomputer system. Behavior Research Methods \& Instrumentation, 1978, 10, 254-258.

DE Villiers, $P$. Choice in concurrent schedules and a quantitative formulation of the law of effect. In W. K. Honig \& J. E. R. Staddon (Eds.), Handbook of operant behavior. New York: Prentice Hall, 1977.

Schwartz, B. Study of the operant and reflexive keypecks in the pigeon. Journal of the Experimental Analysis of Behavior, 1977, 27, 301-313. (a)

Schwartz, B. Two types of keypecking: Suppression of long but not short keypecks by duration-dependent shock. Journal of the Experimental Analysis of Behavior, 1977, 27, 393-398. (b)

Schwartz, B., \& Gamzu, E. Pavlovian control of operant behavior: An analysis of autoshaping and its implications for operant conditioning. In W. K. Honig \& J. E. R. Staddon (Eds.), Handbook of operant behavior. New York: Prentice Hall, 1977.

Schwartz, B., Hamilton, B., \& Silberberg, A. Behavioral contrast in the pigeon: A study of the duration of keypecking maintained on multiple schedules of reinforcement. Journal of the Experimental Analysis of Behavior, 1975, 24, 199-206.

Schwartz, B., \& Williams, D. R. Two different kinds of keypeck in the pigeon: Some properties of responses maintained by negative and positive response-reinforcer contingencies. Journal of the Experimental Analysis of Behavior, 1972, 18, 201-216.

Ziriax, J. M., \& Silberberg, A. Discrimination and emission of different keypeck durations in the pigeon. Journal of Experimental Psychology: Animal Behavior Processes, 1978, 4, 1-21.

(Received for publication May 8, 1980) 